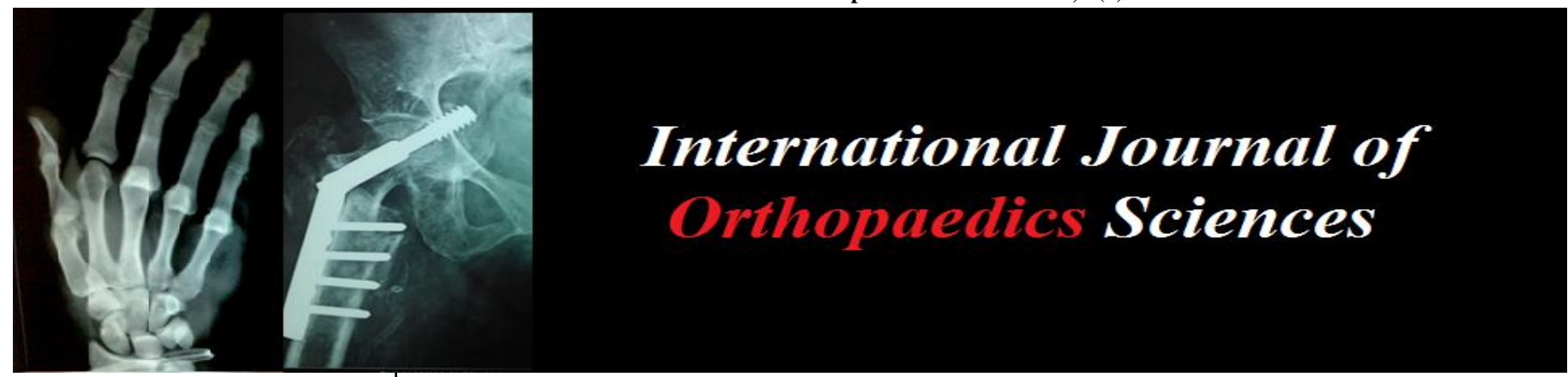

ISSN: $2395-1958$

IJOS 2019; 5(3): 76-78

(C) 2019 IJOS

www.orthopaper.com

Received: 20-05-2019

Accepted: 22-06-2019

\section{Mohammed Abdul Azeem}

Associate Professor in the

Department of Orthopaedics,

Dr. VRK Women Medical

College, Aziz Nagar, Hyderabad,

Telangana, India

\section{Ravindra Patil}

Associate Professor in the

Department of Orthopaedics,

Dr. VRK Women Medical

College, Aziz Nagar, Hyderabad,

Telangana, India
Correspondence

Ravindra Patil

Associate Professor in the

Department of Orthopaedics,

Dr. VRK Women Medical

College, Aziz Nagar, Hyderabad,

Telangana, India

\section{A single antibiotic \& early discharge in orthopaedic}

\author{
Mohammed Abdul Azeem and Ravindra Patil
}

DOI: https://doi.org/10.22271/ortho.2019.v5.i3b.1512

\section{Abstract}

Background: Prophylactic antimicrobials play an important role in the prevention of surgical site infections (SSI), which is one of the most preventable causes of postoperative complications. It is not clear whether the perioperative prophylaxis of a portion of anti-infective agents is sufficient to prevent wound contamination. The purpose of this test was to evaluate whether the fight against infection of a perioperative part was successful in counteracting.

Methods: Participants were administered a single antibiotic of $1 \mathrm{~g}$ of cefotaxime intravenously 30 minutes before surgery followed by 12 hourly for 3 days. Patient were mobilised after 12 hours and discharged on $3^{\text {rd }}$ day. The incidence of postoperative complications such as wound infections, wound resuturing, etc. was monitored.

Results: The study included 50 clean and closed orthopaedic operations out of which only one patient had superficial wound infection. The organisms isolated from wound infection were E. coli, Pseudomonas, which were sensitive to co-trimaxozole. The normal duration of the stay was only 3 days. Conclusions: A single antibiotic of cefotaxime is equally effective, early mobilization and early discharge is useful and safe for orthopaedic surgery.

Keywords: Antimicrobial prophylaxis, Infection of the surgical site, early mobilization, early discharge, orthopaedics

\section{Introduction}

Antimicrobials are the best revelation of the twentieth century. In the pre- antimicrobial era, infectious diseases accounted for significant morbidity and mortality. All this changed with the use of antimicrobials and the 'golden era of antimicrobials' saw a dramatic fall in the mortality from infections. But the revelation seems to be short lived due to irresponsible and erratic use of these drugs has resulted in drug resistance in many organisms. It issued cautioning that across the board utilization of antimicrobials to treat ailments is delivering progressively tranquilize safe diseases everywhere throughout the world ${ }^{[1]}$.

A surgical site infection (SSI) is an infection that occurs after surgery in the part of the body where the surgery took place ${ }^{[2]}$. Surgical site infections remain among the main causes of post-operative morbidity, prolonging hospitalization and increasing the cost of medical treatment in surgical units ${ }^{[3]}$. Antimicrobials play an important role in preventing and treating surgical site infections ${ }^{[4,5]}$. Surgical chemoprophylaxis is an important measure before any surgery to prevent SSI. Nearly 30-50\% of antimicrobials used in hospitals are prescribed for surgical prophylaxis. Antimicrobials are often used in wrong doses, for too long, multiple doses and with too broad spectrum of antimicrobial activity ${ }^{[6]}$. Antimicrobials as prophylaxis for SSI in orthopedic surgeries are indicated when prostheses are implanted, or when any sort of osteosynthetic materials such as nails, wires, plates and screws are used ${ }^{[7]}$.

That's why drug therapy should be scrutinized at international, national, regional and institutional level and efforts are required to evolve a consensus protocol and policy for the same. In our country, due to lack of adequate information and guidelines for antimicrobial prophylaxis in surgery there is a need to generate baseline data on the pattern of use of prophylactic antimicrobials.

Therefore, this study was undertaken with the following aims and objective:

A) To study the pattern of surgical chemoprophylaxis;

B) To find out the rate of wound infection in patients undergoing elective orthopaedic surgical procedure; 
C) Early mobiziation

D) Early discharge.

E) To find out common organisms causing post-operative wound infection.

\section{Materials and Methods}

This study was conducted in the Department of Orthopedics, Dr. VRK Women Medical College, Aziz Nagar, Hyderabad, Telangana.

\section{Inclusion Criteria}

All patients aged 18 years or more, irrespective of their gender, Hypertensive, scheduled for clean, elective orthopaedic surgical procedure and receiving prophylactic antimicrobials were included in the study.

\section{Exclusion criteria}

Patients with open fracture, secondary procedures, DM, Hypo or Hyperthyrodism, history of allergy to any antimicrobials, preoperative infectious disease at the time of admission, receiving any antimicrobials more than 24 hours prior to surgery, and patients not willing to give consent were excluded from the study.

\section{Discussion}

Many studies on the efficacy of antimicrobial prophylaxis in orthopaedic surgery have been reported; some have shown the efficacy of antimicrobial prophylaxis and have recommended that prophylactic antimicrobial use should be limited to the 24 $\mathrm{h}$ following surgery. Moreover, some studies have suggested that drug-resistant organisms appear at higher rates in association with the amount of postoperative antimicrobial usage ${ }^{[8]}$.

In our study, hospital stay was 3 days which is lightly higher than in study done by Giri et al. in Nepal $(2.1 \pm 1.36$ per patient), by Abula et al. (2.17 per patients) in Ethiopia and by Prashanth et al. in India (3.42 per patient) ${ }^{[9-11]}$.

In our results we used cefotaxime and similar done by Kulkarni et al. in India particularly Ceftriaxone and Cefotaxime preferred ${ }^{[14]}$, Similar results were found in study done by Khorrami et al. in Iran, Hassan et al. in Egypt, Salman et al. India, Kumar et al. in India, Yeap et al. in Malaysia, Vyas et al. in India ${ }^{[12,15-16]}$.

Various guidelines also recommends cefazolin $1 \mathrm{gm}$ intravenous single dose or maximum of 3 doses 8 hourly for 24 hours postoperatively as preferred antimicrobial for surgical prophylaxis of clean orthopaedic surgical procedure with implant or clean contaminated surgical procedure. ${ }^{17,18}$ Gram-positive bacteria, i.e., Staphylococci which are the most common cause of infectious complications associated with fracture surgery. Cephalosporins (such as cefazolin) are appropriate first-line agents for most surgical procedures, targeting the most likely organisms and avoiding broadspectrum antimicrobial therapy that can lead to the development of antimicrobial resistance ${ }^{[19]}$.

In our study antimicrobial prophylaxis was started 12 hours preoperatively, given intraoperatively at the time of induction of anesthesia and continued postoperatively BID for 3 days in wards and discharge. Our Patient stay was lesser to study done by Kulkarni et al. $(6.38+2.2$ post-operative days $)$ in India, Giri et al. (6.38 \pm 5.35 days) in Nepal, Chen et al. (6.4 days) in Taiwan, Khorrami et al. $(6+5$ days $)$ in Iran but lower than study done by Hassan et al. $(12.4 \pm 10.9$ days $)$ in Egypt [9, 14-16]. Current US guidelines recommend administration of antimicrobial prophylaxis within $120 \mathrm{~min}$ or
60 min of incision ${ }^{[20,21]}$

European guidelines recommend administration of prophylaxis within $60 \mathrm{~min}$ of incision [17]. The American Association of Orthopaedic Surgeons guideline showed that there is no evidence to support that antimicrobials continued beyond 24 hours provided additional benefits ${ }^{[18]}$. Most studies have demonstrated efficacy of postoperative antimicrobial prophylaxis for only 12 hours or less: whenever short and long courses are compared, the shorter course has proven equally effective ${ }^{[23,24]}$. How ever in our study, the antibiotic given for 3 days.

Dellinger et al. demonstrated that a prolonged course of 5days antimicrobial administration was not superior to a 1-day course for the prevention of fracture site infections [21]. Strachan advocates short-term antimicrobial prophylaxis ${ }^{[25]}$. Gaetani et al. also recommend short-term antimicrobial prophylaxis in orthopaedic and traumatologic surgeries ${ }^{[26]}$. Current best evidence from the literature, based on data from meta-analyses [27]. Cochrane review has not shown a difference between single-dose preoperative antimicrobial prophylaxis and multiple-dose prophylaxis ${ }^{[28]}$. Our results were similar to different studies in which parenteral route was preferred for surgical antimicrobial prophylaxis $[10,15,16]$. The parenteral route is preferred because of its reliability to achieve adequate tissue concentrations ${ }^{[21]}$.

\section{Conclusions}

A Single antibiotic of cefotaxime is equally effective, early mobilization and early discharge is useful and safe for orthopaedic surgery. The resistance of microorganisms can be prevented with this prophylactic single antibiotic.

\section{References}

1. World Health Organization. Report of the World Health Organization on infectious diseases. Overcoming antimicrobial resistance. World Health Report 2000; Geneva: World Health Organization, 2000.

2. Mangram AJ, Horan TC, Pearson ML, Silver LC, Jarvis WR. Hospital Infectious Practices Advisory Committee. Guidelines for the prevention of surgical infection, 1999. Infect Control Hosp Epidemiol. 1999; 20:250-78.

3. Fleming A. Penicillin. Nobel Conference, 1945. Available at http: //www.nobelprize.org / Medicine / Laureates / 1945 / fleming-lecture.pdf.06 [access 06/01/13].

4. Rehospitalizations After Treatment for SSI Add $\$ 10$ Million to $\$ 65$ Million to Healthcare Costs. Available at http://www.infectioncontroltoday.com/news/2012/06/ rehospitalizations-after-treatment-for-ssi-add-10-a-65million-to-health-costs.aspx. [Access 01.06.13].

5. Perencevich EN, Sands KE, Cosgrove SE. Health and the economic impact of surgical site infections It is diagnosed after hospital discharge. Emerg Infect Dis. 2003; 9:196-203.

6. Holzeheimer RG, Haupt W, Thiede A, Schwarzkopf A. The challenge of postoperative infections: Fa Does the surgeon make a difference? Infect Control Hosp Epidemiol. 1997; 18:449-56.

7. Court-Brown CM. Antibiotic prophylaxis in orthopedic surgery. Scand J Infect Dis. 1999; 70:74-9.

8. Kato D, Maezawa K, Yonezawa I, Iwase Y, Ikeda H, Nozawa $\mathrm{M}$ et al. Prospective randomized Study on prophylactic antibiotics in clean orthopedic surgery in a ward for 1 year. J Orthop Sci. 2006.

9. Giri BR, Pant HP, Shankar PR, Sreeramareddy CT, Sen 
PK. Surgical site infection and Antibiotics use pattern in a tertiary care hospital in Nepal. J Pak Med Assoc. 2008; 58(3):148-51.

10. Abula T, Kedir M. The model of antibiotic use in hospitalized surgical patients of a university hospital, north-west Ethiopia. Ethiop. J Health Dev. 2004; 18(1):34-8

11. Prashanth $P$, Narendranath $S$, Geetha M, Naveen Kumar M, Patil N, Reshma SR. Trends in prescription. Antimicrobials in postoperative rooms in a tertiary hospital. Drug Invention Today. 2011; 3(12):301-4.

12. Salman MT, Akram MF, Rahman S, Khan FA, Haseen MA, Khan SW. Model of prescription drugs in Surgery rooms of a university hospital in northern India. Indian Journal for the Practicing Doctor, 2008, (2).

13. Kasteren E, Mannien J, Ott A, Kullberg B, Boer A, Gyssens. Antibiotic prophylaxis and risk of surgical site infections after total hip arthroplasty: timely administration is the most important factor. CID. 2007; 44(1):921-7.

14. Kulkarni RA, Kochhar PH, Dargude VA, Rajadhyakshya SS, Thatte UM. Models of antimicrobial use of surgeons in India. Indian J Surg. 2005; 67:308-15.

15. Khorrami M, Tabatabaei S, Ahmadarabi M. Efficacy of short-term versus long-term antibiotic treatment in the prevention of deep infections after orthopedic procedures (prospective observational study). Jundishapur J Microbiol. 2012; 5(2):427-9.

16. Hassan A, Ibrahim O, Guinaidy M. Surveillance of the use of antibiotics and resistance in the orthopedic ward of an Egyptian university hospital. Int $\mathbf{J}$ Infect Control. 2011; 7(1):1-10.

17. Scottish guidelines for interconnection guidelines (SIGN) 104. Antibiotic prophylaxis in surgery. A national clinical guide. Edinburgh, United Kingdom: Sign, 2008. Available at http: // www.sign.ac.uk/pdf/sign104.pdf (access September 10, 2012).

18. American Academy of Orthopedic Surgeons. Statement of information on recommendations for the use of intravenous antibiotic prophylaxis in primary total arthroplasty of, 2004.

19. Kumar S, Behera B, Faroocco K, Sharma V, Mathur P. Journal of the Physicians Association of India. 2010; 58(1).

20. Bratzler DW, Houck PM, Richards C et al. Use of antimicrobial prophylaxis for major surgery: initial results of the National Project for the Prevention of Surgical Infections. Surg Arch. 2005; 140:174-82.

21. Dellinger EP, Gross PA, Barrett TL. Quality standards for antimicrobial prophylaxis in surgical procedures. American Infectious Diseases Society. Clin Infect Dis. 1994; 18:422-7.

22. Harbarth S, Samore MH, Lichtenberg D, Carmeli Y. Prolaped antibiotic prophylaxis after cardiovascular surgery and its effect on surgical site infections and antimicrobial resistance. Circulation. 2000; 101:2916-21.

23. Pollard JP, Hughes SP, Scott JE, Evans MJ, Benson MK. Antibiotic prophylaxis in total hip replacement. Br Med J. 1979; 1:707-9.

24. Heydemann JS, Nelson CL. Short-term preventive antibiotics. Clin Orthop Relat Res. 1986; 205:184-7.

25. Strachan CJ. Antibiotic prophylaxis in peripheral vascular surgery and prosthetic orthopedics. J Antimicrob Chemother. 1993; 31(B):65-78.

26. Gaetani G, Carozzi S, Schiesari L, Ferrari PG, Simoncini
F. Short-term prophylaxis in orthopedic and traumatological surgery. Chir Ital. 1986; 38(1):113-8.

27. Southwell-Keely JP, Russian RR, March L et al. Antibiotic prophylaxis in hip fracture surgery: a metaanalysis. Clin Orthop Relat Res. 2004; 419:179-84.

28. Gillespie WJ, Walenkamp G. Antibiotic prophylaxis for fractures of the proximal femur and other closed bone fractures. Cochrane Syst Rev Database, 2001, (1). CD000244. 